\title{
Analysis of Current Status and Causes of Maritime Accidents
}

\author{
Qunsheng Chen \\ Marine College of Shandong Jiao Tong University \\ Weihai, China 264200 \\ E-mail: alexjmu@163.com \\ Shouwen Pang \\ Marine College of Shandong Jiao Tong University \\ Weihai, China 264200 \\ Haifeng $\mathrm{Hu}$ \\ Marine College of Shandong Jiao Tong University \\ Weihai, China 264200
}

\author{
Xin Qi \\ Marine College of Shandong Jiao Tong University \\ Weihai, China 264200 \\ Xiaoli Meng \\ Marine College of Shandong Jiao Tong University \\ Weihai, China 264200 \\ Zhuanzhao Liu \\ Marine College of Shandong Jiao Tong University \\ Weihai, China 264200
}

\begin{abstract}
This paper analyzes the current situation of shipwreck in the world today according to the data network of the world maritime shipwreck data, as well as the maritime report of International Maritime Organization, combined with a distinctive feature of the shipwreck which occurred in recent years, brings forward some precaution measures and finds out the root cause of maritime accidents. This paper points out that the root causes of sea accidents is ship management. Various factors, especially the major effect of the artificial factors are concluded through analysis of specific maritime cases. Sea accidents can be reduced by inspection and control of the ship, ship operating management and navigation, and improve the quality of personnel. This paper also puts forward rational proposals to prevent sea pollution, ensure safety of life at sea and enhance the overall safety of the shipping.
\end{abstract}

Keywords-sea accident; man-made factors; ship management; specific measures

\section{INTRODUCTION}

Since the 1990s, with the acceleration of world trade liberalization, economic integration and globalization of information, world shipping industry has been greatly developed. The total tonnage of the world's merchant has increased. The trend of ship enlargement, automation and high speed has become increasingly outstanding. At the same time, the loss of ship and amount of marine insurance claimed caused by various kinds of shipwreck have increased. And the shipwrecks of certain types of ships (such as oil tankers, chemical tankers) are harmful to the marine environment and human survival.

For the past few years, the general trend of world disaster accident has slowed down, but it is still not optimistic that the number of maritime accidents remains at a high level. Therefore, how to avoid the sea accidents to achieve the goal of IMO "safer shipping, cleaner ocean", becomes a hot topic of the attention and research. Researches showed that there were many factors that could lead to shipwreck accidents, most of which can be divided into two types: human factors and natural factors. In fact, many disasters caused by natural factors are related to human activities. In order to improve navigation safety, concrete countermeasures to prevent sea accidents will be introduced through analyzing the factors affecting safety of navigation in the paper.

\section{SituAtion OF THE SHIPWRECK IN THE WORLD}

In recent years the number of accidents has indicated reduction due to improved hull structure, navigational equipment and technology, as well as the improvement of the relevant international treaties. Compared with the previous century, the shipwrecks nowadays have changed with respect to the quality and quantity. Its ratio is also reduced relative to the ship's in possession. In 2004 the total loss vessels all over the world amount to 402, and in 2013, 213. The so-called total loss ships mean that ships sink due to fire, collision, and damage, etc. of which all the damaged hull can no longer be used. Relative to the ship's total loss from the ship's in possession known as the ratio of total loss, which is generally noted with total tonnage or counter. Due to ship enlargement, it is appropriate to note the ratio of total loss with counter. In the past half a dozen years ago the ratio of total loss was $0.72 \%-0.55 \%$, in the last few years $0.46 \%$. It basically tends to decrease except for a few years increasing by accident.

More than $80 \%$ of the causes of the shipwrecks are human errors. No matter how well made, the navigation of the ship is manipulated by the ship officer. The disaster, firstly, is caused by shipping technology; and secondly, it is engaged in the marine safety management by the ship 
company. Therefore, it is practicable to evaluate the level of navigation technology of the country according to the situation of ship disaster and the state of ship's registry. From 1927 to 1936 , the total loss rate of Japan is 26 times as much as the United States, which is known as one of the greatest disaster countries in the world. 70 years later, the Japanese ship's in possession has dramatically increased. Then Japan scrapped old ship, actively improved ship quality, modernized the ship and improved shipping technology. Now, in terms of the safety of the ship sailing, Japan has become a reliable shipping country in the world.

From the point view of the ship's age of world total loss of the ship from 2005 to 2013, the total loss of the older age ship increases, namely: 0-4 years, $4.6 \%$; $5-9$ years, $5.6 \%$; 10 -14 years amounts to $16.5 \%$; $15--19$ years, $26.7 \%$. The actual situation in 2013 : total loss of the ship from 20 to 24 years for 213 vessels, accounting for 27.2 percent, while its number of vessels takes up only $15.2 \%$ of whole ship kind, thus the total loss of the vessel constitute rate / retain Boats constitute total loss rate is approximately 1.79 .

TABLE I. The Situation of The Total Loss ShiPs WorLdWide

\begin{tabular}{|c|c|c|c|}
\hline $\begin{array}{c}\text { nationality of } \\
\text { ship's registry } \\
\text { (country) }\end{array}$ & $\begin{array}{c}\text { ship in } \\
\text { possession } \\
\text { (annual } \\
\text { average) }\end{array}$ & $\begin{array}{c}\text { number of } \\
\text { total loss ship } \\
\text { (annual } \\
\text { average) }\end{array}$ & $\begin{array}{c}\text { ratio of total } \\
\text { loss ship } \\
\text { (annual } \\
\text { average) }\end{array}$ \\
\hline Taiwan & 628 & 7.4 & 1.18 \\
\hline Korea & 1995 & 12.8 & 0.64 \\
\hline Panama & 5089 & 30.9 & 0.61 \\
\hline Greece & 1953 & 8.1 & 0.41 \\
\hline Liberia & 1586 & 4.6 & 0.29 \\
\hline Japan & 9935 & 24.3 & 0.24 \\
\hline Germany & 1383 & 2.3 & 0.17 \\
\hline Norway & 2185 & 5.0 & 0.23 \\
\hline America & 6311 & 12.9 & 0.20 \\
\hline Spain & 2329 & 7.3 & 0.31 \\
\hline
\end{tabular}

In the past 8 years, the number of total loss ships has been 1890, of which 752 occurred in the Pacific Ocean, accounting for about 40\%, 493 occurred in the Atlantic Ocean, about $26 \%$. These two areas accounted for $66 \%$ of the worldwide total loss ships because most of the world's maritime trade by ship transport is in these two navigable waters. Specifically in these two waters, the number of total loss ships in the Western Pacific accounted for about 30\% in East Asia (including Japan) as the center of the western Pacific. Similarly, the number of the total loss vessels in the Eastern Atlantic Area centers on Western Europe and West Bank of Africa accounted for $19 \%$. The number of total loss vessels in these two regions accounted for about half of the world total loss ship. There were a lot of total loss ships in the Indian Ocean and the Mediterranean Sea and other waters. The number of the total loss vessels in the Caribbean (including Bermuda sea is called the devil waters) accounted for $6 \%$. According to Lloyd's register statistics, the world total loss vessel accidents are divided into the following seven categories: flooding, sinking, missing, fire and explosion, collision, striking on rocks, and other factors. During 8 years from 2005 to 2013, there were many total loss vessels particularly because of flooding and sinking, accounting for $42 \%$ of the total loss ships, damage, wreckage about $21 \%$, fire, explosion, about $15 \%, 78 \%$ of the other three. From 2005 to 2013 casualties caused by the ship shipwreck totaled 10013, about 100 people annually. Most deadly sea accidents is resulted from collision, accounting for $42 \%$ of the total number of casualties; Injuries caused by flooding, sinking accounted for $40 \%$, the total of the two added up to $82 \%$, which became the main reason of casualties.

According to the data record of shipwreck, there were 677 accidents. 27 of the accidents resulted in ship scrapping, accounting for $3.99 \%$, total loss ships were 312 , and accounting for $46.08 \%$. Divided by dwt, the deadweight of the majority of the ships involved in accidents were less than 100,000 t i.e. 638 ; divided by hull form, the number of bulk carrier involved in accident is 432 , accounting for $63.81 \%$ of the total number of accidents; according to age of the ships, the average age of 677 ships is 23.9 years, the number of aging and overage vessels which are older than 20 years is 391 , accounting for $57.75 \%$ of the total.

\section{ACCIDENT ANALYSIS OF TODAY'S SHIPWRECK}

In the records of shipwreck, the most common causes of the accidents are collisions, including collisions between the ships and the fixture between ship fittings, adding up to 313 , accounting for $46.23 \%$. Followed by fires and explosions, there are 203, accounting for $29.99 \%$.

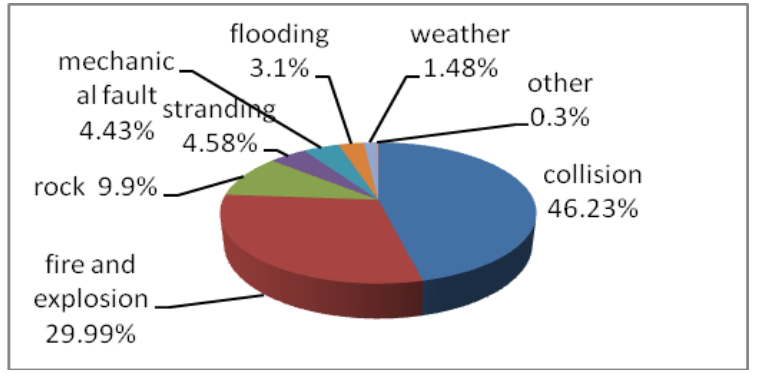

Fig. 1. Accident Analysis of Today's Shipwreck

This shows that collision and fire and explosion are the main reasons of shipwreck, it is important to pay special attention to avoiding such accidents. The shipwreck factors can be divided into two types: human factors and natural factors. In practice, many natural disasters are related to human activities, such as inappropriate use of equipment, instrument and device, inaccurate guide of the program, failing to follow the correct procedure, improper stowage reducing the ship's stability, and so on. Some of the actors leading to the shipwreck are unexpected or beyond human control, however the human factors are very important. For example, many accidents are due to driver's negligence and faults. Statistics shows that $80 \%$ of average sacrifice of ships, machine damage and pollution accidents are caused by 
human factors such as the shortfalls in ship management and crew qualification and errors of management, manifested in: (1) paying less attention to the safety of navigation; (2) the crew members' subnormal state of mentality and the inadequate quality of the crew.

\section{A. Human Factors}

Man-made factors, especially the human errors are the main causes of the sea accidents, which has become the consensus of Marine industry. In fact, more than $80 \%$ of the maritime accidents are caused by human errors; in addition, in recent years the accident data of studies have shown that fatigue is an important cause of human errors. Artificial errors caused by fatigue are the main cause of large amounts of sea accidents.

1) Shipwreck caused by old facilities and human errors.

At 8:58 on April 16, 2014, the vessel" SEWOL" carrying 470 people, flooding accident occurred while the ferry sank in waters off southwestern South Korea. The accident occurred on the way from the Incheon port to Jeju Island. The South Korean ship carrying 476 people, with the total weight of 6825 tons issued a distress signal off the screen island $20 \mathrm{~km}$ (12 miles). 293 people died in the accident, 172 injured and 11 people missed. In addition 150-180 cars and 1,157 tons of goods were damaged.

A large number of escape devices on the "SEWOL" hardly played a role in the accident. There were 44 lifeboats in the passenger ship, among which only two were opened. No escape boat was opened though there were four which could hold one thousand people. Design flaw, unreasonable modification, overloading, and improper use on life-saving equipment constitute the internal causes of the accident. When the ferry course was changed suddenly, the cargo fixed on the ship shifted to another side and the vessel sank rapidly after losing center of gravity. The wrong course operation directly resulted in the shipwreck.

2) Shipwrecks caused by malfunction and Sailing in violation of international rules.

On October 6, 1983, the vessel "Daqing 236" belonging to Guangzhou Marine bureau carrying more than 15000 tons of crude oil was sailing in sea from Qinhuangdao port to Huangpu, then the ship "carat Bart Hill" was found to sail round the back of "Daqing 236". At around 10:00, "carat Bart Hill" suddenly came up to "Daqing 236". "Daqing 236" took emergency measures to avoid collision. But "carat Bart Hill" hit the port aft by the bow. "Daqing 236" began flooding and sank soon. According to the Hong Kong Marine Department's report, the steering gear of "carat Bart Hill" failed to work. Fortunately 59 mariners in distress were rescued.

The main responsibility of the accident lied in "carat Bart Hill", which was in violation of the international regulations for preventing collisions due to overtaking and crossing the "Daqing 236" ship. "carat Bart Hill" sailed to Hong Kong and reported the accident process to local Maritime Bureau. "carat Bart Hill" was in the voyage sailing from Japan to Hong Kong. Shortly after leaving Japan its steering gear failed, however, the ship continued to sail with such risks.
Because of the rudder failure, the ship abnormally crashed into "Daqing 236" leading to the accident.

3) Shipwrecks caused by stranding and improper operation

On April 12, 2006, 0300, the ship "zhexiangji807" belonging to a Zhejiang Xiangshan company stranded at Niubi landscape GongSheng reef rocks. The hull was damaged after being forced off the reef. When sailing to the waters near the four corners of the mountain, the ship sank at 0545 hours. All six crew members on board were rescued.

The ship violated the rules and carried out improper operations when navigating in fog. It is the main reason to cause the stranding for deviation from the planned route. In accordance with the relevant provisions of the "People's Republic of China Seamen on Duty Rules" and" Rules for Sailing in the Fog", the officer on watch should report to the captain and strengthen the duty when the Ship was sailing in the restricted visibility in rocky waters. However, throughout the process, the captain was not notified and the crew also did not strengthen the duty, which left hidden unsafely. The duty officer failed to maintain proper alertness and use the good seamanship.

The ship damage was expanded due to the improper disposition. The captain of the ship arranged the crew to examine the damaged part and implemented plugging and drainage. But he did not fully study a variety of objective circumstances, such as the prevailing circumstances, the tide and the anti-settling properties of the ship itself etc. Therefore the captain failed to develop comparative sound plan to rid the ship of the reef.

\section{B. The vessel herself}

1) Too old ship. The designed service life of bulk carrier is generally 15 years. The vessel of more than 20 year's age will not be registered in some countries. But the average life of bulk carriers is about 25 years, because the benefit of 10 years ago must be at least $50 \%$ over 15 years. Shipping companies try to extend the service life of the ship. Then the proportion of the aged and superannuated ships is increased. According to statistical analysis of the accidents of the ships more than 500GT from 2000 to 2014, the loss rate of the ship used for $0-4$ years is $0.13 \%$; $5-9$ years is $0.16 \%$; $10-14$ years is $0.11 \%$; $15-19$ years is $0.78 \% ; 20-24$ years is $1.29 \%$. Obviously, the greater the age of the ship, the higher the loss rate. It shows that aging vessels and sea accidents have a direct relationship.

2) Unseaworthiness of vessel. Marine casualties caused by unseaworthiness of the ships are very common. Ships with any of the following situations before proceeding to the sea are considered to be unseaworthy.

a) insufficient strength or defectiveness of the hull and machinery equipment;

b) lacking or defective of the shipboard equipment, such as defective piping systems, Insufficient or improper 
work of anchor, rudder, compass, the necessary life-saving equipment and communication equipment;

c) Lack of staff or unqualified crewmember;

d) Inadequate fuel, materials, or provision;

e) Not suitable for loading certain goods;

f) Without the whole or necessary certificates and documents for navigation.

\section{Force majeure such as natural disasters and other external factors}

According to the analysis of the shipwreck accidents occurred from January 2002 to March 2009, most shipwreck accidents result from the disaster of bad weather. Loss of 29 bulk carriers was due to the weather disaster, taking up $42 \%$ of total quantity. The average age of total loss bulk carriers was 20.3 years.

\section{Summary OF Measures to Reduce the OCCURRENCE OF SEA ACCIDENTS}

By analyzing the situations and causes of the shipwrecks in the world, the preventing measures are concluded as follows, inspection work before departure, the response during the voyage, in addition, the ship maneuvering, strengthening ship operations management and improving the quality of maritime personnel are also very important.

\section{A. Inspection before departure}

The implementation of PSC and ISM requires ships to maintain a good technical condition.

1) Evaluate the safety of the ship equipment to deal with emergency situations. Following projects should be evaluated and inspected: marine mechanical and electrical equipment (main engine and donkey engine e.g.), navigation handling equipment (steering and anchor, etc.), positioning equipment (ollision-avoidance system and autopilot, etc.) communication equipment, lifesaving and fire-fighting equipment and admiralty charts and publications and so on. Moreover, it is important to determine if the vessel is seaworthy.

2) Inspection and evaluation of hull structure. First check the stress corrosion of the hull structure; the hull strength depends on the corrosion of structural components. Some parts rust severely.

3) Stowage. The stress of the hull according to the stowage plan should be less than that calculated on the instruction. The following factors should be taken into considerations: whether to carry out freighting according to hold capacity or not; whether the cargo stowed in hold evenly; whether there are inappropriate broken stowage and ballast or not; loading in turn reasonably. In any stage of loading, make sure that every cargo compartment is within the limit of the maximum hydrostatic pressure and the bending moment and trimmed reasonably. Besides, ensure the water-tightness of the cargo hold, and the hatchway covers, every hold and passageway are in good conditions.

\section{B. Inspections underway}

It's too late to find the danger and lose the favorable opportunity to take measures in earlier time, which is the main reason to encounter severe perils of the sea, and then suffer a great loss. However, there have also been in a timely manner, taking emergency measures correctly and having saved the cargo and the lives of the crew. Therefore, check on the voyage and good manipulation is an important means to avoid the accident of the perils of the sea.

1) Deck patrol. Check each ballast tank and bilge tank before and after the big waves.

2) Routine inspection. Four corners of hatch-end coaming, whose center is easy to crack, especially several big holds close to the midship should be inspected. From the point of the lateral of the deck, the focus of the inspection should be mainly the two-thirds of the medial from its outer edge to center area; From the perspective of the vertical of the deck, a few tanks in the front and at the back of the ship, especially the main deck plate butt seam and top border of the tanks in the front and at the back of the ship should be mainly inspected.

3) omplete inspection of the side cabinet. The focus of the check is the longitudinal ribs under the main deck. The rusty upper longitudinal ribs are more serious than the lower one onboard the superannuated ship. The inspection of the bottom side cabinet may be carried out with the tank drainage.

\section{Ship handling}

It is suggested to make full use of good seamanship to avoid damage resulted from the severe sea condition. Strive for and take full advantage of all favorable factors to avoid danger when proceeding in rough sea. Once appears, take effective measures to head off the danger in time. While sailing in the rough sea, the propulsion, buoyancy and stability should be kept.

\section{To strengthen the operation management of the ship}

Relevant management personnel should take the check of ships' seaworthiness seriously. Shipping companies should be more serious, because potential safety hazard can cause irreparable damage. Port State Control (PSC) is considered to be the last line of the defense of maritime security. PSC plays an increasingly vital role in ensuring marine safety, protecting maritime environment and implementing the safety standards of IMO. Experiences have proven that PSC, especially by the regional and even the global cooperation, is the most effective way to promote maritime safety and environmental protection.

\section{E. To improve navigation personnel quality}

The cause of the sea accidents is most closely related to the operating personnel management. Thus it is necessary to strengthen the safety consciousness of operators and improve their operating skills in order to reduce accidents. The shipping company should conduct regular Maritime safety consciousness education and safety skills training. Carry out 
regular inspections and maintenances of the ship to ensure that the equipments are in good condition. Popularize safety knowledge to improve the quality of the crew. Education programs on safe production shall be carried out in shipping companies. Furthermore, the crewmembers had better learn more knowledge about safe production and master the security technology.

\section{CONCLUSION}

By analyzing the situations and causes of the shipwrecks in the world, this paper puts forward preventing measures in the beginning and during the voyage. The shipping enterprises have to enhance their management level to change this unfavorable situation. Finally the ship deficiency rate and incident rate will decline. Mr. Mitropoulos said in Argentina on 30 June, 2006 that, the sea had always been a potentially hazardous and dangerous working environment and it remained so today, despite the great technological advances that had been developed. In order to achieve safe, secure and efficient shipping on clean oceans, IMO and all the administrations shall be united to facilitate the implementation of maritime safety standards, reinforce the supervision of seafarers to ensure that sailors can handle the ship skillfully. Moreover, it is necessary to train and examine them professionally before they work on board a ship and build up a strict qualification system.

\section{REFERENCES}

[1] Lou Rui. Average Ship Towing [J]. Navigation Technology. 2014 (6), P31-32.

[2] Wong Zhimin, Xu Jianhua. Shipwreck Figure of MOL Comfort [J]. China Ship Survey. 2014 (10), P50-53.

[3] Leslie J. Buglass, Marine Insurance and General Average in the United State $[\mathrm{M}]$. second edition.

[4] Marine Accident Investigation Branch, U.K. MaiB Annual Reports 2001. 2002. London: Author.

[5] Guo Qishun. Navigational Safety Should be Alarm Bells Ringing [N]. China Ship News. 2000-12-20 (6).

[6] Wang Chuanxu. Large Bulk Vessels Shipwreck Reasons and Protective Measures [J]. Marine Technology News and Trends. 1994(9), 6-8.

[7] IMO. SOLAS, Consolidated Edition, 1997. London: the Author.

[8] Kuo, C. Managing ship safety. 1998. London: LLP Reference Publishing. P108-109. 